\title{
Simulation of Asymmetric Destabilization of Mine-void Rock Masses Using a Large 3D Physical Model
}

\author{
X. P. Lai ${ }^{1,2} \cdot$ P. F. Shan ${ }^{1,2} \cdot$ J. T. Cao ${ }^{1,2} \cdot$ F. Cui ${ }^{1,2} \cdot$ H. Sun ${ }^{1,2}$
}

Received: 20 September 2014/ Accepted: 14 March 2015/Published online: 24 March 2015

(C) The Author(s) 2015. This article is published with open access at Springerlink.com

\begin{abstract}
When mechanized sub-horizontal section top coal caving (SSTCC) is used as an underground mining method for exploiting extremely steep and thick coal seams (ESTCS), a large-scale surrounding rock caving may be violently created and have the potential to induce asymmetric destabilization from mine voids. In this study, a methodology for assessing the destabilization was developed to simulate the Weihuliang coal mine in the Urumchi coal field, China. Coal-rock mass and geological structure characterization were integrated with rock mechanics testing for assessment of the methodology and factors influencing asymmetric destabilization. The porous rock-like composite material ensured accuracy for building a 3D geological physical model of mechanized SSTCC by combining multi-mean timely track monitoring including acoustic emission, crack optical acquirement, roof separation observation, and close-field photogrammetry. An asymmetric 3D modeling analysis for destabilization characteristics was completed. Data from the simulated hydraulic support and buried pressure sensor provided effective information that was linked with stress-strain relationship of the working face in ESTCS. The results of the 3D physical model experiments combined with hybrid statistical methods were effective for predicting dynamic hazards in ESTCS.
\end{abstract}

P. F. Shan

shanpengfei571571@126.com

1 School of Energy and Mining Engineering, Xi' an University of Science and Technology, Xi' an 710054, China

2 Key Laboratory of Western Mines and Hazard Prevention, Ministry of Education of China, Xi' an 710054, China
Keywords Asymmetric destabilization · Extremely steep and thick coal seam (ESTCS) - Mechanized sub-horizontal section top coal caving (SSTCC) - 3D physical modeling · Multi-mean timely track monitoring

\section{Introduction}

There are a substantial number of coal seams around the western part of China that have seam thicknesses of greater than $20.0 \mathrm{~m}$ and angles exceeding $45^{\circ}$, which are referred to as extremely steep and thick coal seam (ESTCS). In complicated geological and mining settings, coal-rock masses of mine voids that fail after coal mining may be induced by the hybrid physical-mechanics coupling effects of tectonic stress, excavation disturbed stress, and seismic forces (Alehossein and Poulsen 2010; Lai et al. 2014). Under such high stress-disturbances, asymmetric deformation of coal-rock masses in mine voids is significantly different in ESTCS (Kose and Tatar 1997; Lai et al. 2009a, b). Local strength degradation of surrounding rock may occur by asymmetric destabilization of mine voids that evolve into dynamic derivative hazards and are referred to as coal burst and dynamic collapse (Cai et al. 2005).

In the Urumchi coal field, located in the northwestern meizoseismal region of China (Dzungaria Basin), there are approximately 3.6 billion tonnes of measured and indicated coal that lie in the ESTCS category (Zhang and Lai 2008). The traditional longwall mining technique is unstable for the ESTCS with significant coal loss and poor surrounding rock structure, which not only can influence the production efficiency, but also may induce more potential hazards from mine voids similar to dynamic rock mass destabilization (Simsir and Ozfirat 2008a, b; Lauriello and Fritsch 1974; Tu et al. 2009; Kelly et al. 2001). 
As a given coal mining method, mechanized SSTCC, a particular kind of top coal caving (Xie and Zhao 2009), provides a powerful method to extract ESTCS in such a complicated underground circumstance. Specifically, top coal caving in ESTCS is a completely different method compared with longwall top coal caving (LTCC) in gently inclined coal seams due to limited lengths of the working faces (Vakili and Hebblewhite 2010; Zhang et al. 2011; Unver and Yasitli 2006). Generally, the length of the working face is shorter than the maximum length of 50.0 $\mathrm{m}$, and the multi-narrow mine voids are above the mechanized SSTCC workings. Hence, the variability of stress and deformation in ESTCS are different from that of LTCC in gently inclined coal seams (Lai et al. 2014; Cao et al. 2011; Miao et al. 2011).

There have been numerous efforts to solve the relative hazards of dynamic rock mass destabilization with various methods (Lai et al. 2014). However, previously published literature on the destabilization characteristics of surrounding rock mainly focused on understanding the destabilization mechanisms of LTCC that are involved in slope-stress analysis, hazard-control design, and optimization and policy-making (Yasitli and Unver 2005). Jha and Karmakar (1992) investigated the factors affecting production, while Singh et al. (1992) investigated strata behavior during caving and dilution of caved top coal under in-situ conditions. Singh (1999) determined the formation and behavior of the immediate roof on 2D physical models in the laboratory, and Dian (1992) made a comparison between slice mining and top coal caving methods.

$\mathrm{Wu}$ (1992) tried to determine factors affecting the dilution of coal. Yasitli and Unver (2005) used the finite difference code FLAC ${ }^{3 \mathrm{D}}$ to optimize the crucial parameters of LTCC at the Omerler Underground Mine with in-situ conditions. However, there are a limited number of studies (e.g., Trueman et al. 2008) on mining dynamic hazard in ESTCS with effective three-dimensional physical model that can directly reveal the cause of coal-rock mass failures from mine voids after coal mining. Few studies have referred to evolution mechanism of mine voids with induced stress in meizoseismal region.

The mining dynamic hazards that have occurred in ESTCS at Urumchi Coal field are novel. Hybrid monitoring combined with $3 \mathrm{D}$ physical modeling is one way to theoretically predict dynamic rock mass hazards. Traditional prediction approaches for dynamic hazards were not applicable for ESTCS, and were neither analyzed nor studied in detail using a monitoring index (acoustic-seismic-wave) and their implicit relations. Particularly, the stress of deeper coal-rock mass was disturbed by collapse of the steep-broken coal-rock masses, and the magnitude of broken intensity related to the spatial-temporal-strength relation and mining disturbance. Inevitably, the indicated stress redistribution of coal-rock masses leads to the occurrence of dynamic hazards (Diaz Aguado and Gonzalez 2009).

Destabilization in the host rock mass was largely controlled by the discontinuities and structural features. In this paper, a methodology was developed for assessing destabilization potential of the host rock mass from mine voids.

The analytical method illustrated in Fig. 1 involves the development of a geomechanical model to account for asymmetric destabilization characteristics of the host coalrock mass from mine voids. Development of a detailed geomechanical model is described and involves amalgamation of in-situ geological and mining settings, necessity of large-scale model, model material, and model device selection with hybrid monitoring. The 3D physical model provides information that can be used during mine excavation in ESTCS where asymmetric destabilization of host rock masses will be minimized and will make deep mining with effective hazard prevention possible.

\section{Background}

\subsection{In-situ Geological and Mining Settings}

The Weihuliang coal mine at Urumchi coal field serves as a case study to illustrate the asymmetric destabilization characteristics of rock masses from mine voids (Fig. 2). The Weihuliang coal mine is located in the pre-Cenozoic strata, approximately centered at the city of Urumchi. Insitu geological and physical settings of the case study are totally distinct (Lai et al. 2014). Fierce crushing stress is a crucial characteristic of tectonic stress and the seismic mechanism is mainly influenced by fracture of a thrust fault. Crustal movement and tectonic activity frequently

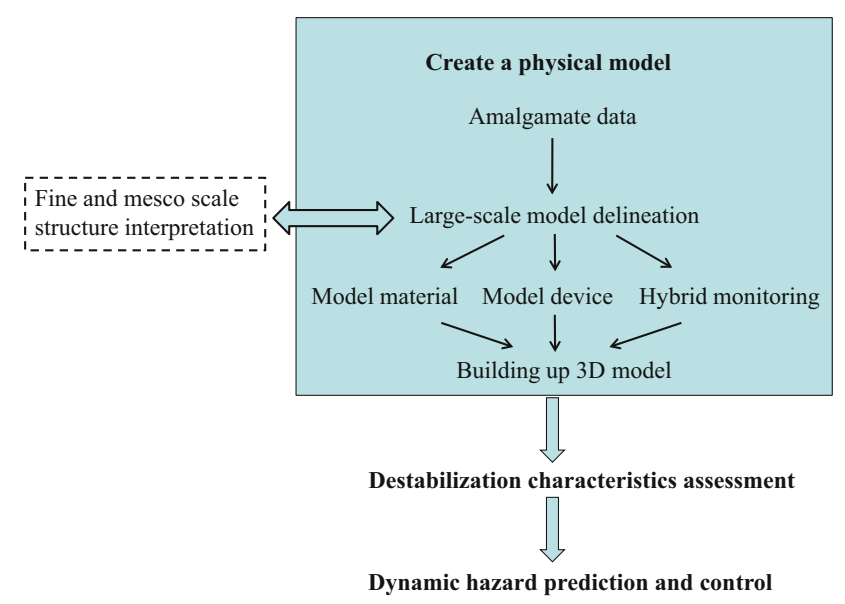

Fig. 1 Analysis of methodology for assessing asymmetric destabilization characteristics of surrounding rock from mine voids 


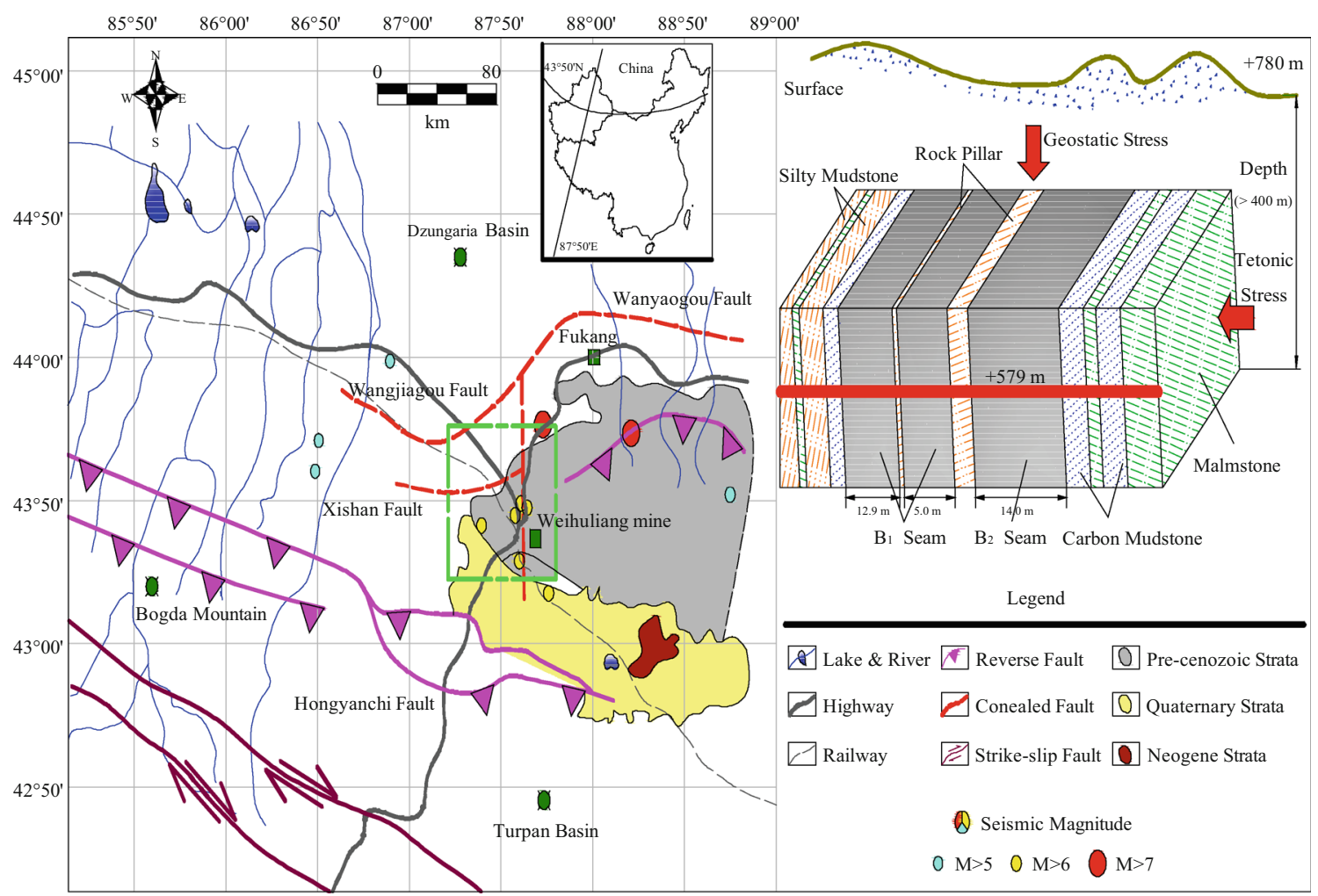

Fig. 2 Profiles of the Urumchi coal field including geological situation and sectional map with main lithostratigraphic units

occur and result in diastrophism velocity reaching up to $10 \mathrm{~mm}$ per year. Diastrophism is an elastico-plastic behavior, whereby plastic-shear failure occurs in the faults with strong mobility. Seismic loading would induce rock mass slide and collapse in large underground chambers when coal is extracted near past fault or well-developed joint fissure zones.

The Xishan-Wangjiagou fault group of the Urumchi coal field is located in a conversion region between a faultfold structure of northern Tianshan Mountain and a nappe structure of Bogda Mountain. The fault-fold structure of northern Tianshan Mountain is composed of several reverse faults whose spatial span is about $30 \mathrm{~km}$. The basin with a southward nappe is formed by the Xishan fault group where the depth of decollement is greater in the north and shallower in the south but generally is $10-15 \mathrm{~km}$. All faults in the Xishan fault group converge to the decollement whose cover depth is about $11 \mathrm{~km}$. Urumchi coal field is composed of the Badaowan syncline and Qidaowan anticline. Weihuliang coal mine is located in the Badaowan syncline with other coal mines. The total thickness of the Weihuliang coal mine is $513.77-902.90 \mathrm{~m}$ with $40 \mathrm{~m}$ of coal-bearing strata above the mine and a total thickness of approximately $117.05-175.45 \mathrm{~m}$. Strike and dip angles of minable seams are $322^{\circ}-335^{\circ}$ and $46^{\circ}-67^{\circ}$, respectively. The seam angles vary from $63^{\circ}$ to $88^{\circ}$ in
ESTCS. $\mathrm{B}_{1}$ and $\mathrm{B}_{2}$ seams are extremely thick and available for practical excavation in the $\mathrm{J}_{2} \mathrm{x}_{1}$ strata. The mechanical condition of the $\mathrm{B}_{1+2}$ seams is relatively poor, because the incompact roof and floor do not meet prerequisite characteristics that are suitable for large-level mechanized SSTCC. However, large-scale "V" collapse grooves are formed in the surface after top coal caving and would allow precipitation to pour into the collapse grooves and induce destabilization of roof surrounding rock. Vast noxious gases assembled in the mine voids have been developed by irregular mining and continual excavation disturbance. Usually, the extra-high section height of the top coal does not hinder abrupt large-scale collapse of rock masses that may be induced by local variations of horizontal stress, methane accumulation, mine flood, or fire and coal dust with recovery process; hence, it is necessary to develop an effective methodology for assessing destabilization of rock masses with potential hazards.

\subsection{Mechanism of Asymmetric Destabilization}

The working face of the mechanized SSTCC could be horizontal to the direction of an ESTCS with short actual length for all staff operation. A finite-size excavation disturbed zone (EDZ) after coal mining would be regarded as a neo-active-like fault structure. Deformation of coal-rock 
masses is intensively concentrated on a narrow zone called an asymmetric destabilization zone under high strain rate loading. Theoretically, we have a stability analysis method for mechanical conditions and stress-strain relationships of plastic destabilization for the asymmetric destabilization of surrounding rock with abundant numerical simulations, which provides a profound understanding of asymmetric destabilization characteristics.

We pay little attention to micro-structures, which play a key role in prediction and control of the asymmetric destabilization. Because in-situ monitoring methods are limited for micro-structure evolution mechanisms on dynamic mechanical response parameters of asymmetric destabilization, we have seldom effectively uncovered the destabilization mechanism. Also, we should analyze the asymmetric destabilization characteristics with hybrid microscopic and macroscopic methods. Currently, we have developed a series of basic experimental materials and structures.

(1) Fine-scale (millimeter size) rock damage test was applied for quantitative analysis of mechanical properties with MTS-AE (acoustic emission) in varisized specimens.

(2) Multiphase medium physical simulation meso-scale (centimeter size) experiments have been used to realize spatio-temporal evolution characteristics of different media.

However, a specific large-scale experiment (meter size) should be built to scientifically realize mechanical conditions, evolution mechanisms, and macro-structure characteristics of the asymmetric destabilization. Particularly, asymmetric destabilization of coal-rock masses should be accurately predicted and used for optimization of operational facilities.

Equations on the asymmetric destabilization of coalrock masses after coal mining are established by state vectors theory. "Damage-deformation-AE" characteristics of coal-rock masses have been revealed with different static-dynamic loading modes and were used to predict the asymmetric destabilization characteristics based on $\mathrm{AE}$ state vectors. The model would be regarded as a countable region that was composed by $N$ continuous units.

In time $t, V_{i}(x, y, t)$ was the $i$ th weight of $V(x, y, t)$ in the $i$ th sub-domain, and N-dimensional vector $\vec{V}(t)$ has been established as Eq. (1).

$\overrightarrow{V_{t}}=\left(V_{1}, V_{2}, \cdots V_{i}, \cdots V_{n}\right)$

Difference value of $\mathrm{N}$-dimensional vector $\vec{V}(t)$ would be another $\mathrm{N}$-dimensional vector in adjacent two time $t-\Delta t$ and $t$ as Eq. (2).
$\Delta \vec{V}_{t-\Delta t, t}=\vec{V}_{t}-\vec{V}_{t-\Delta t}$

To describe the $\vec{V}(t)$ change, a new scalar value, module of $N$-dimensional vector $\vec{V}(t), M_{0}$ was applied to state general level of the whole physical field as Eq. (3).

$M_{0}=|\vec{V}(t)|$

We defined angle $(\Phi)$ as being between $\vec{V}_{t-\Delta t}$ and $\vec{V}_{t}$ Another module of $\left|\vec{V}_{t-\Delta t, t}\right|, \Delta M_{0}$ stated physical field variation in the other view. The value of $M_{0}$ and $\Delta M_{0}$ explained coal-rock masses damage situation. They would increase distinctly with internal damage increased in the model, which can be described by AE total event and energy rate.

\section{Simulation Preparation}

\subsection{Determining Similarity Coefficient and the Model Device}

A particular model frame is required for developing a specific large-scale experiment. The model device must initially be stiff enough to ensure the stability of the model in the experiment. With current requirements in a simulation experiment, five kinds of rock masses were considered including carbon mudstone, silty mudstone, malmstone, $\mathrm{B}_{1}$, and $\mathrm{B}_{2}$ seam. Based on the geological section of the coal seam, the angle of the coal seam is over $64^{\circ}$ and falls into the extremely steep and thick coal seams. We determined that, in the simulation scope, the excavation level of the Weihuliang mine had already dropped to $+574 \mathrm{~m}$ with the mechanized sub-horizontal section top coal caving from $+625 \mathrm{~m}$ for the whole excavation level. So, approximately $49.00 \mathrm{~m}$ was considered in the vertical direction. According to the geological section, the thickness of the simulation seam was $110.00 \mathrm{~m}$, where the thicknesses of the $B_{1}$ and $B_{2}$ seams were, respectively, 16.90 and $14.00 \mathrm{~m}$. For the actual simulation of the excavation in the trend, $72.50 \mathrm{~m}$ was used as the width for the simulation because it represented the advance distance (per month) of the working face. Finally, we determined that constant of geometric similarity $\left(C_{l}\right)$ with comprehensive consideration of all experimental conditions using:

$C_{l}=l_{m} / l_{p}=0.04$

In which, $m$ represents the model parameter, and $p$ is the parameter of in-situ rock masses. According to the properties of the simulation material and the ratio of the rock masses, the constant of density similarity $\left(C_{\rho}\right)$ is represented by Eq. (5). 
$C_{\rho}=\rho_{m} / \rho_{p}=0.68$

Using the similarity principle and dimensional analysis, the constant of geometric similarity $\left(C_{l}\right)$, the constant of density similarity $\left(C_{\rho}\right)$, the constant of stress similarity $\left(C_{\sigma}\right)$, and the constant of time similarity $\left(C_{t}\right)$ are related by Eq. (6).

$C_{\sigma}=C_{\rho} C_{l} C_{t}=\left(C_{l}\right)^{1 / 2}$

The constant of stress similarity is 0.0272 , and the constant of time similarity is 0.2 . Considering the depositional pattern of the original strata, we established the large 3D model with $0.01 \mathrm{~m}$ in length direction. Due to the complex geological settings, an extensive number of faults were distributed throughout the research area. The model was unable to simulate all geological structural planes; thus, we emphasized the crucial fault that closely neighbored the $\mathrm{B}_{2}$ seam. Furthermore, a projected coordinate system was used to locate all parts accurately in the model.

The model device not only applied geostatic stress as an analog ground stress, but also co-located loading equipment in the horizontal direction simulating in-situ tectonic stress as an auxiliary stress and as a dynamic load for the model. Ultimately, large underground structure experiment system (LUSE) was modeled as (length $\times$ width $\times$ height) $4.42 \mathrm{~m} \times 2.90 \mathrm{~m} \times 1.95 \mathrm{~m}$ in the Xi'an University of Science and Technology (XUST), China. The greatest sizes of the system is $8.80 \mathrm{~m} \times 5.60 \mathrm{~m} \times 12.00 \mathrm{~m}$.

The large underground structure experiment system, to date is the largest device of its kind in Asia, and has several favorable aspects including loading ability, geometric size, and monitoring methods.

\subsection{Physico-Mechanical Settings of Coal-Rock Masses}

Core samples from geo-climatic boreholes in the experimental site were classified using the rock quality designation (RQD) system. The designation system provides a quantitative method of categorizing the engineering character of rock masses based on core hole information. A summary of the RQD for the boreholes is presented in Table 1, which shows, in general, that the RQD of rock masses of the extremely steep and thick coal seams at
Weihuliang coal mine was low. Locally, mudstone and malmstone were broken and had extremely low RQD values.

The physico-mechanical properties of the main sedimentary rock masses used in the large physical simulation were based on evaluation of exploratory drilling and laboratory test results. In addition, the data utilized in the experiment were finished at Key Laboratory of the Ministry of Education of China for Western Mines and Hazard Prevention at Xi'an University of Science and Technology. The main properties used in the physical simulation were summarized in Table 2.

\subsection{Determining the Model Material and Proportion}

Much research work has been done on model material (Lai et al. 2012, 2013; Li et al. 2011; Pan et al. 1997). In the present work, we prepared a new kind of modeling material for establishing the specific three-dimensional model. Porous rock-like composite material (PRCM) adopted bank sand as the aggregate, with $3.9 \%$ in the $0.50-1.00 \mathrm{~mm}$ size range, $29.1 \%$ in the $0.25-0.50 \mathrm{~mm}$ size range, and the remaining portion in the $0.10-0.25 \mathrm{~mm}$ size range. We used bank sand and coal powder as the aggregate for the coal seam material being simulated. Gypsum and flour were both grouting agents and water was used as the plastic impact agent, which largely influenced the accuracy of the material proportion. The porous rock-like composite material was light material whose massive density was $1700 \mathrm{~kg} / \mathrm{m}^{3}$. Pebbles, clay, and mica were added separately to represent the fault and distinguish between different strata. Pebbles and clay were used to simulate the fault and improve the brittleness of the model material.

The nonlinear coupling effect of porous rock-like composite material is remarkable because of the plastic impact agent (Huang 2009; Lin 1984; Lai et al. 2013a, b). Because the porous rock-like composite material consisted of loose particles, their mechanical properties are anisotropic. Comprehensive strength of porous rock-like composite material depends on nonlinear coupling effect with water. In some cases, various ingredients would blend well with water, whereas, in other cases, the alternation effect of water on the material plays a key role in deciding
Table 1 Rock quality designation (RQD) for the Weihuliang coal mine

\begin{tabular}{llll}
\hline Rock type & RQD $(\%)$ & RQD description & Integrality description \\
\hline Carbon mudstone & 21 & Bad & Broken \\
Silty mudstone & 38 & Bad & Broken \\
Malmstone & 29 & Bad & Broken \\
B $_{1}$ seam & 56 & Medium & Relative integrality \\
B $_{2}$ seam & 67 & Medium & Relative integrality \\
\hline
\end{tabular}


Table 2 Physico-mechanical properties of main sedimentary rock masses

\begin{tabular}{llllclc}
\hline Rock definition & $\begin{array}{l}\text { Density } \\
\left(\mathrm{kg} / \mathrm{m}^{3}\right)\end{array}$ & $\begin{array}{l}\text { Bulk modulus } \\
(\mathrm{GPa})\end{array}$ & $\begin{array}{l}\text { Poisson } \\
\text { ratio }\end{array}$ & $\begin{array}{l}\text { Cohesion } \\
(\mathrm{MPa})\end{array}$ & $\begin{array}{l}\text { Friction angle } \\
(\mathrm{degree})\end{array}$ & $\begin{array}{l}\text { Compressive strength } \\
(\mathrm{MPa})\end{array}$ \\
\hline Carbon mudstone & 2460 & 8.75 & 0.231 & 3.20 & 42.0 & 11.0 \\
Silty mudstone & 2510 & 13.50 & 0.217 & 1.20 & 30.0 & 18.4 \\
Malmstone & 2487 & 19.50 & 0.238 & 13.60 & 24.7 & 24.7 \\
B $_{1}$ seam & 1300 & 5.10 & 0.320 & 6.70 & 26.4 & 10.6 \\
$\mathrm{~B}_{2}$ seam & 1340 & 5.30 & 0.235 & 6.12 & 23.2 & 13.7 \\
\hline
\end{tabular}

strength of the modeling materials. Therefore, modeling of these effects must consider a comprehensive set of properties including static pressure $(\mu)$ and hydrodynamic pressure $\left(\tau_{d}\right)$. The effective stress of porous rock-like composite material $\left(\sigma_{a}\right)$ could be divided into three stages (Lai et al. 2013a, b).

Stage I Modeling material is unsaturated. In such a situation, under an external loading, the pore water would not provide enough internal stress $(\sigma)$ to create internal micro-cracks and dilatancy in the material and decrease the strength of the material. In this stage, along with increase of water, the unprofitability of static pressure would be gradually decreased and strength of the porous rock-like composite material is steadily increased while the effective stress of the material is increased, as expressed by Eq. (7).

$\sigma_{a}=\sigma-\mu$

Stage II Modeling material is saturated. Under an external loading, drainage equilibrium process occurred among internal pores with the structure of the material stabilized, which would result in the skeleton and pore water bearing the external loading. The beneficial static pressure for the skeleton reaches peak value and the effective stress of the porous rock-like composite material reaches the maximum, as expressed by Eq. (8).

$\sigma_{a}=\sigma+\mu$

Stage III Modeling material is oversaturated. Under such a condition, all pores are filled with flowing water that would add an extra hydrodynamic pressure and shear stress that results in incremental and tangential deformation in the skeleton. Micro-cracks are evolved into macro-cracks that may cause dynamic destabilization and damage the whole structure. Under these conditions, the mechanical properties of the porous rock-like composite material are less stable. Meanwhile, the effective pressure is sharply decreased, as expressed by Eq. (9).

$\tau_{d}=R \times J$

In which, $R$ and $J$ are coefficient of hydrodynamic pressure and hydraulic slope angle, respectively. When flowing water streams in the porous rock-like composite material, macro-cracks would propagate remarkably forming the macro-crack plane, and the extra hydrodynamic pressure is parallel with the plane and internal static stress is perpendicular to the plane at the same time. So, $R$ would be regarded as $b r / 2$. Here, $b$ is weighted width of the macro-crack plane, and $r$ is unit weight of the water in the experiment. Besides, $J$ meets the Darcy's law.

The strength of the porous rock-like composite material was adjusted by changing contents of aggregate and grouting agents. Mainly, the compressive strength and bulk modulus of the porous rock-like composite material were analyzed. Standard coal-rock specimens $(\phi 50 \times 100 \mathrm{~mm})$ with different ingredients have been made and each group had nine specimens with the same ingredients avoiding such errors. Plastic impact agent for the specimens in the experiment was water whose amount just occupied one in every ten units of the aggregate and grouting agents. Figure 3 showed stressstrain relationship of coal-rock specimens with various ingredients being adopted in the simulation.

Proportions (coal:sand:gypsum:flour) comprising the coal seam were 30:30:4:6 and 30:30:3:7, in the experiment. Maximum axial deformation of specimens with 30:30:4:6 was $1.6 \%$, and had an elastic deformation stage that was lower than the uni-axial stress, peak values of compressive strength and bulk modulus were $13.7 \mathrm{MPa}$ and $5.3 \mathrm{GPa}$, respectively. While the proportion was altered to 30:30:3:7 with a reduction in the amount of gypsum, specimens obtained peak values of compressive strength and plastic stage. However, compressive strength and bulk modulus decreased to $10.6 \mathrm{MPa}$ and $5.1 \mathrm{GPa}$, respectively. Compared with mechanical parameters of the prototype, we finally decided the model proportions of various rock masses. Tables 3 and 4 separately indicated the main mechanical parameters of the porous rock-like composite material and the state of model placement and the amount for different materials.

\section{Experimental Results}

\subsection{Model Experiment Layout}

When the model was completed, we began to set all monitoring facilities and dry the model out for at least 

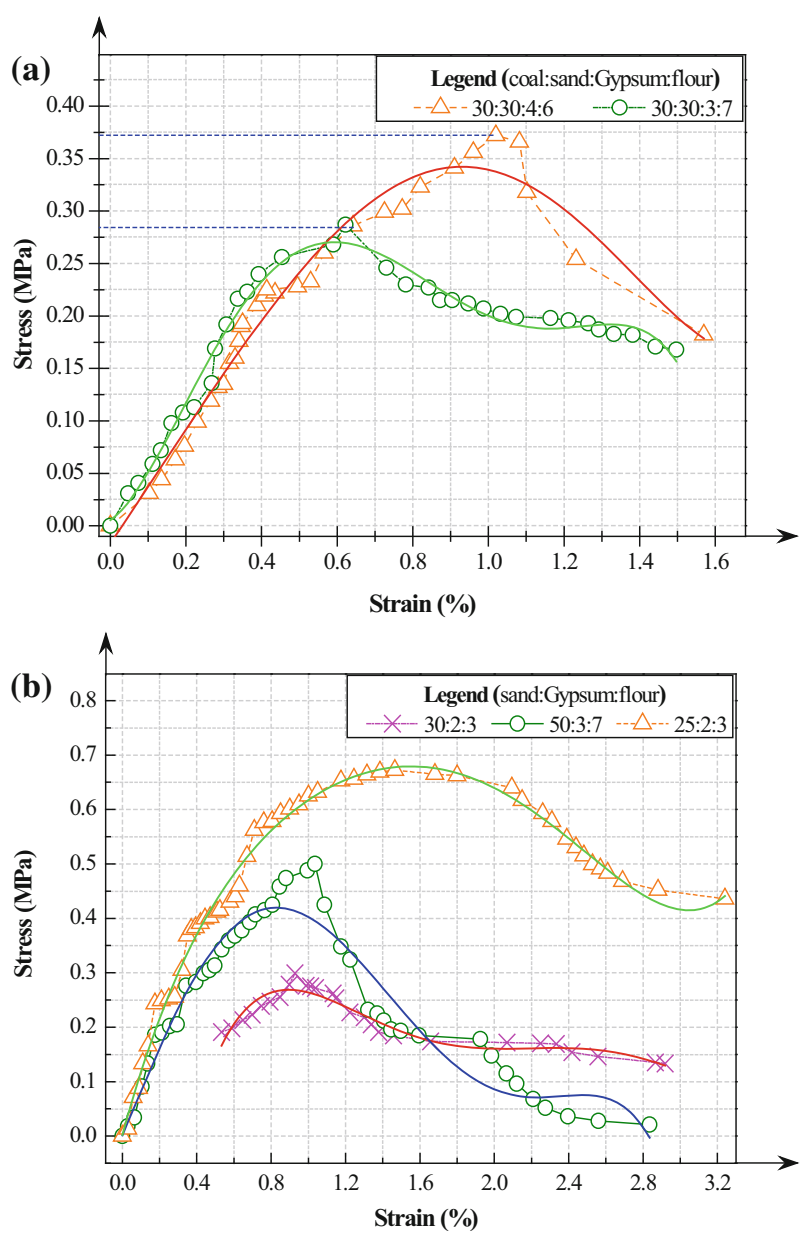

Fig. 3 Stress-strain curves of the porous rock-like composite material under uni-axial compressive loading for the experiment, a stressstrain relationship of the material for coal seams; b stress-strain relationship of the material for various rock masses

2 months so the strength of the model were able to reach an ideal state. The mining and observation of the model complied with parameter of the constant of time similarity, and as a matter of experience and custom, we used $1 \mathrm{~h}$ to simulate one equivalent day. The roof collapsed method was adopted in the model and, first, caved the upper level seam at the $+579 \mathrm{~m}$ level in Weihuliang mine to simulate the actual mine voids, as shown in Fig. 4 a.
Multi-mean timely track monitoring including acoustic emission (AE) sensors, crack optical acquirement (COA), roof separation observation (RSO), and close-field photogrammetry (CFP) was applied. Data from the buried pressure sensor (BPS) was linked with the stress-strain relationship of the stope in the extremely steep and thick coal seams. Simulated hydraulic support (SHS) was simulated for parameter optimization of hydraulic supports in the extremely steep and thick coal seams. We measured the initial conditions of all facilities before coal mining. The mechanisms of asymmetric destabilization characteristics of rock mass from mine voids were clearly detected and analyzed, as shown in Fig. 4b.

Hydro-cylinders located on top and on the lateral side of the large underground structure experiment system exerted the asymmetric static-dynamic loading for the experimental purpose, which simulated the tectonic stress derived from fault-fold structures of the northern Tianshan Mountain and nappe structure of Bogda Mountain. The maximum loading of the top and lateral hydro-cylinders were 10 and $12 \mathrm{MPa}$, respectively.

\subsection{AE Characteristics of Asymmetric Destabilization}

Asymmetric destabilization characteristics would induce local deformation and failure of coal-rock masses, which are predisposed to mine hazards. Stress around the working face must be redistributed after coal mining by using abundant AE data on failure of the surrounding rock. We set up AE sensors in different locations to achieve information induced by rock failure in four stages, which were (I) excavation of working face, (II) first caving of top coal, (III) coal caving, and (IV) local roof caving. Figure 6 showed the mechanism of asymmetric destabilization-AE in various stages.

Initially, the model was excavated; the AE signal was less with seldom total and big events due to good condition of coal-rock masses (Fig. 5a), when the working face just advanced $0.5 \mathrm{~m}$. With the working face advancing continuously, integrality of coal-rock masses was beginning to
Table 3 Main mechanical parameters of the material in various proportions

\begin{tabular}{llll}
\hline Matching & $\begin{array}{l}\text { Bulk modulus } \\
(\mathrm{GPa})\end{array}$ & $\begin{array}{l}\text { Compressive strength } \\
(\mathrm{MPa})\end{array}$ & Field rock mass \\
\hline $\begin{array}{l}\text { Sand:gypsum:flour } \\
\text { 30:2:3 }\end{array}$ & 8.75 & 11.0 & Carbon mudstone \\
50:3:7 & 13.5 & 18.4 & Silty mudstone \\
25:2:3 & 19.5 & 24.7 & Malmstone \\
Coal:sand:gypsum:flour & & & $\mathrm{B}_{1}$ seam \\
30:30:3:7 & 5.1 & 10.6 & $\mathrm{~B}_{2}$ seam \\
30:30:4:6 & 5.3 & 13.7 & \\
\hline
\end{tabular}


Table 4 Specific matching ratio being adopted for the model

\begin{tabular}{lccllccc}
\hline Rock definition & Model thickness $(\mathrm{mm})$ & Total weight $(\mathrm{kg})$ & Sand $(\mathrm{kg})$ & Coal $(\mathrm{kg})$ & Gypsum $(\mathrm{kg})$ & Flour $(\mathrm{kg})$ & Water $(\mathrm{kg})$ \\
\hline Carbon mudstone & 140 & 437.08 & 374.64 & 0 & 24.92 & 37.52 & 43.10 \\
Silty mudstone & 2060 & 6427.20 & 5356.00 & 0 & 321.36 & 749.84 & 642.72 \\
Malmstone & 760 & 2371.20 & 1976 & 0 & 158.08 & 237.12 & 237.12 \\
B $_{1}$ seam & 676 & 2110.74 & 904.49 & 904.49 & 90.58 & 210.91 \\
B $_{2}$ seam & 560 & 1748.32 & 749.28 & 749.28 & 75.04 & 174.72 & 174.83 \\
\hline
\end{tabular}

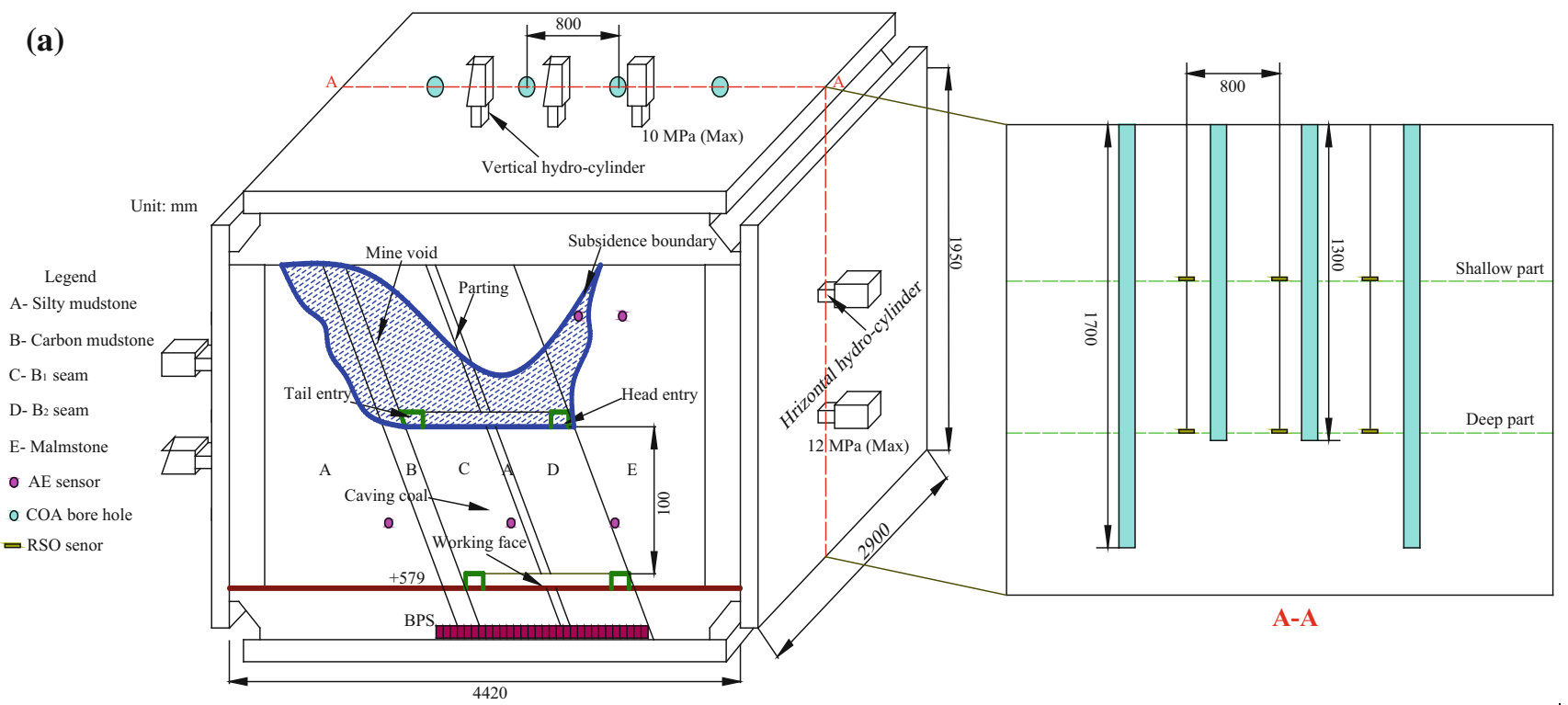

(b)

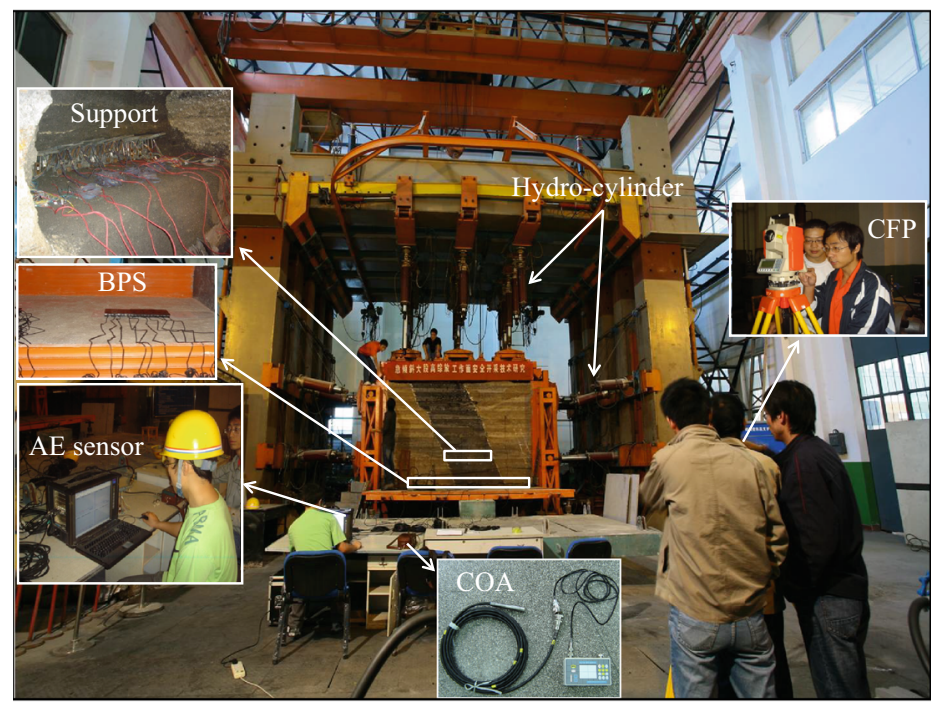

Fig. 4 Layout of model and multi-mean timely track monitoring, a scheme of the large 3D model experiment including general and sectional views; $\mathbf{b}$ presentation of all monitoring facilities in actual experimental condition

be broken and cracks were propagating. During first caving of the top coal, the AE signal waves appeared to skip. The crest value of the $\mathrm{AE}$ event occurred at the No. 33 monitoring serial number. The signal from the No. $5 \mathrm{AE}$ sensor was weaker without severe rock mass failure than others, which indicated that coal excavation and first 
caving of top coal seldom affected the upper zone of the model monitored by the No. $5 \mathrm{AE}$ sensor.

Figure $5 \mathrm{~b}$ indicated that, after first caving of the roof, several small-scale fluctuations of AE signals from the top coal emerged and cracks gradually stretched. Energy rate of coal-rock masses released abruptly up to 600 , and then values of all parameters declined and tended toward a gentle state.

Figure 5c shows the parameter traits after coal caving. A large-scale roof collapsed suddenly and the AE signal surged indicating that added cracks propagated. The coal caving was a dynamic wave process where the total and big event increased to 700 and 650 , respectively. The peak value of energy rate occurred at the No. 37 monitoring serial number. Thereafter, the energy rate was reduced to the point that caving no longer influenced the coal-rock masses.

The roof located upon the top coal started caving in a large scale, with Fig. 5d showing AE characteristics in the process. The AE signal rose and fluctuated repeatedly, with damage increasing to the coal-rock masses. The integrality of 3D internal part model continued degradation. According to $\mathrm{AE}$ trait analysis of the $3 \mathrm{D}$ model, the common mechanism of $\mathrm{AE}$ traits was summarized with parameters of the AE signal emerging as a commutative wave in time, which indicated that cracks in the coal-rock masses were propagating steadily after structural planes alternatively opened and closed. Large and small strain zones continuously alternated with time variation.

\subsection{Model Asymmetric Deformation Characteristics}

\subsubsection{Internal Part of the Model}

The center of the model was regarded as the origin of the coordinate system. We determined coordinate points for the No.1-No.6 boreholes for the crack optical acquirement. In preliminary stages of the experiment, the coal-rock masses were integral in all boreholes and seldom exhibited failure. After first caving of the top coal, coal caving, and roof local caving stages, the various hole walls were destroyed in different situations. Slabbing, lateral crack,
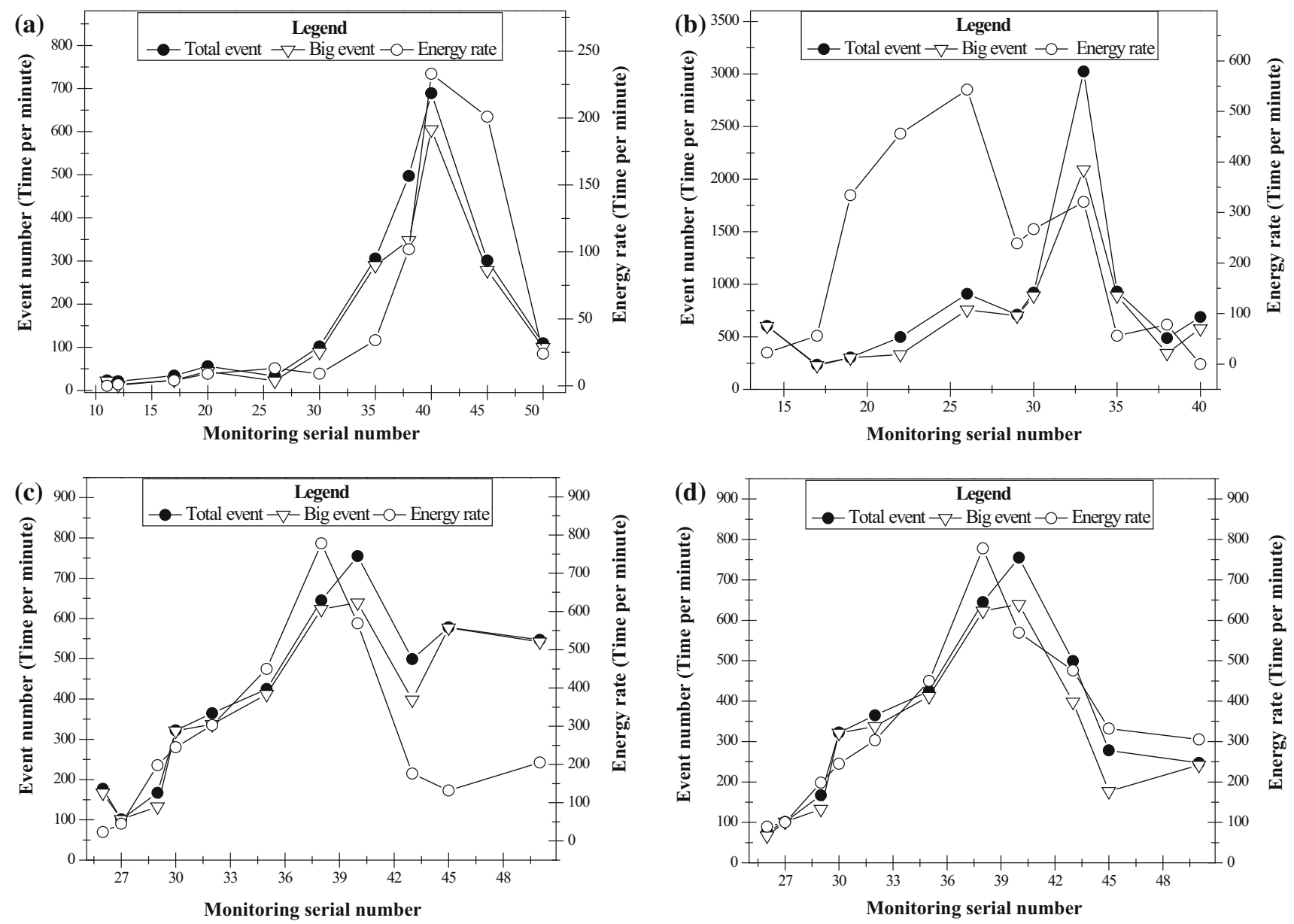

Fig. 5 AE parameters in various stages of the excavation: a working face; $\mathbf{b}$ first caving of top coal; c coal caving; $\mathbf{d}$ roof local caving stage 
oblique crack, scission, disintegration, swelling of hole walls, and oval deformation were the main failure types observed by the crack optical acquirement at the hole walls. Lateral cracks and slabbing emerged in the top coal caving process and were induced by gravity action of the overlying-strata, which resulted in asymmetric displacement of coal-rock masses. Oblique crack and scission were crucial failure types caused by internal shear stress of the 3D model. However, disintegration and swelling of hole walls were caused by stress concentration, oval deformation was caused by asymmetric static-dynamic axial loading acting on the boreholes. Failure of surrounding rock mainly occurred at $0.8-2.1 \mathrm{~m}$. Rock masses of the hole tops and bottoms were seldom destroyed, as shown in Fig. 6a. Macro-cracks and joints were classified on the basis of orientation and depicted using a rose diagram of joints, as shown in Fig. 6b. We determined that six joint orientations were advantageous in the model including SE120 $-130^{\circ}$, SW $240^{\circ}-250^{\circ}$, NW300 $-310^{\circ}$, NW340 $350^{\circ}$, NE $30^{\circ}-40^{\circ}, \mathrm{NE}^{\circ}-70^{\circ}$.

Equation (10) indicated the quantitative statistical relations on macro-crack amounts $(x)$ versus borehole length (y) and provides a theoretical basis for evaluation of asymmetric deformation in the internal part of the model.

$y=0.47206+\frac{4.63924}{1+e^{\frac{x-3.89602}{0.41562}}}$

With the advent of length, crack amounts are fitted by statistical data plotting by the software. Generally speaking, fitting results originating from all bore holes are divided into three stages uniformly. First stage called fracture zone is from 0.0 to $0.5 \mathrm{~m}$ in the boreholes. The amount of macro-crack increases obviously in initial zone of the boreholes, and also reaches the maximum in the end. In sharp contrast, between 0.5 and $0.8 \mathrm{~m}$ in the boreholes (plastic zone), macro-cracks still propagate; however, the quantity of macro-cracks reduces rapidly. Asymmetric destabilization is weakened in the stage being fallen into elastic zone. When borehole length is greater than $1.0 \mathrm{~m}$ (elastic zone), amount of macro-crack stays steady.

\subsubsection{Roof Separation Observation for the Model}

In the experiment, we planted 19 roof separation facilities in the model that were separately located in the shallow and deep parts of the model for monitoring reparation in each stage. In Fig. 7a, the maximum subsidence and minimum subsidence of shallow parts after coal mining were 7.89 and $7.76 \mathrm{~cm}$, and the average value was $7.84 \mathrm{~cm}$ with an average subsidence velocity of $0.163 \mathrm{~cm}$ per hour. After first roof caving, the maximum subsidence and minimum subsidence of the shallow part were 7.83 and $7.75 \mathrm{~cm}$, and the average value was $7.77 \mathrm{~cm}$ with an average subsidence velocity of $0.194 \mathrm{~cm}$ per hour. In third stage (top coal caving), the maximum subsidence and minimum subsidence of the shallow part were 7.74 and $7.52 \mathrm{~cm}$, and the average value was $7.63 \mathrm{~cm}$ with an average subsidence velocity of $0.254 \mathrm{~cm}$ per hour. When a large-scale roof caving emerged, the maximum subsidence and minimum subsidence of the shallow part were 7.48 and $7.10 \mathrm{~cm}$, and the average value was $7.36 \mathrm{~cm}$ with an average subsidence velocity of $0.310 \mathrm{~cm}$ per hour.

The maximum subsidence and minimum subsidence of the deep part (Fig. 7b) was 15.91 and $15.81 \mathrm{~cm}$, and the average value was $15.89 \mathrm{~cm}$ with an average subsidence velocity of $0.330 \mathrm{~cm}$ per hour after coal excavation. After first roof caving, the maximum subsidence and minimum subsidence of the deep part were 15.90 and $15.79 \mathrm{~cm}$, and the average value was $15.87 \mathrm{~cm}$ with an average subsidence velocity of $0.396 \mathrm{~cm}$ per hour. Also, in third stage (top coal caving), the maximum subsidence and minimum subsidence of the deep part were 15.97 and $15.65 \mathrm{~cm}$, and the average value was $15.73 \mathrm{~cm}$ with an average subsidence velocity of $0.520 \mathrm{~cm}$ per hour. Finally, the maximum subsidence and minimum subsidence of the deep part were 15.53 and $15.32 \mathrm{~cm}$, and the average value was $15.43 \mathrm{~cm}$ with an average subsidence velocity of $0.640 \mathrm{~cm}$ per hour after the large-scale roof collapse. According to statistical analysis, accumulative maximum subsidence and minimum subsidence of strata (Fig. 7c) was 0.31 and $0.01 \mathrm{~cm}$, and the average value was $0.07 \mathrm{~cm}$ with an average subsidence velocity of $0.014 \mathrm{~cm}$ per day.

From all of the above listed data, different stages had various influences on the internal situation of the model. Generally, the induced maximum subsidence and minimum subsidence were 15.53 and $15.43 \mathrm{~cm}$. The crest value of separation was $0.31 \mathrm{~cm}$. Under the three-dimensional loading action, separation always emerged in the model. When the working face advanced, the region of mine voids gradually developed and induced separation that evolved into macro-slabbing. Coal-rock masses near the working face would be destabilized in an oblique direction of the seams (Fig. 7d).

\subsubsection{Surface Displacement for the Model}

Surface displacement monitoring points were scattered at superficies of the model and were divided into seven rows $(\mathrm{a}-\mathrm{g})$ in which eleven points were arranged. The row spacing was $300 \mathrm{~mm}$, which was prerequisite to predicting local defects of surrounding rock by observing the surface displacement of the model.

Figure 8 shows the close-field photogrammetry results with comprehensive statistics. The points in row a were so far away from the working face that the value was smaller, which indicated that initially top coal caving had less of an 
Fig. 6 Crack distribution characteristics around asymmetric destabilization rock masses, a shows hybrid assessment of internal deformation and crack distribution, also the specific layout of the crack optical acquirement is given. b Rose diagram of joints in the COA borehole

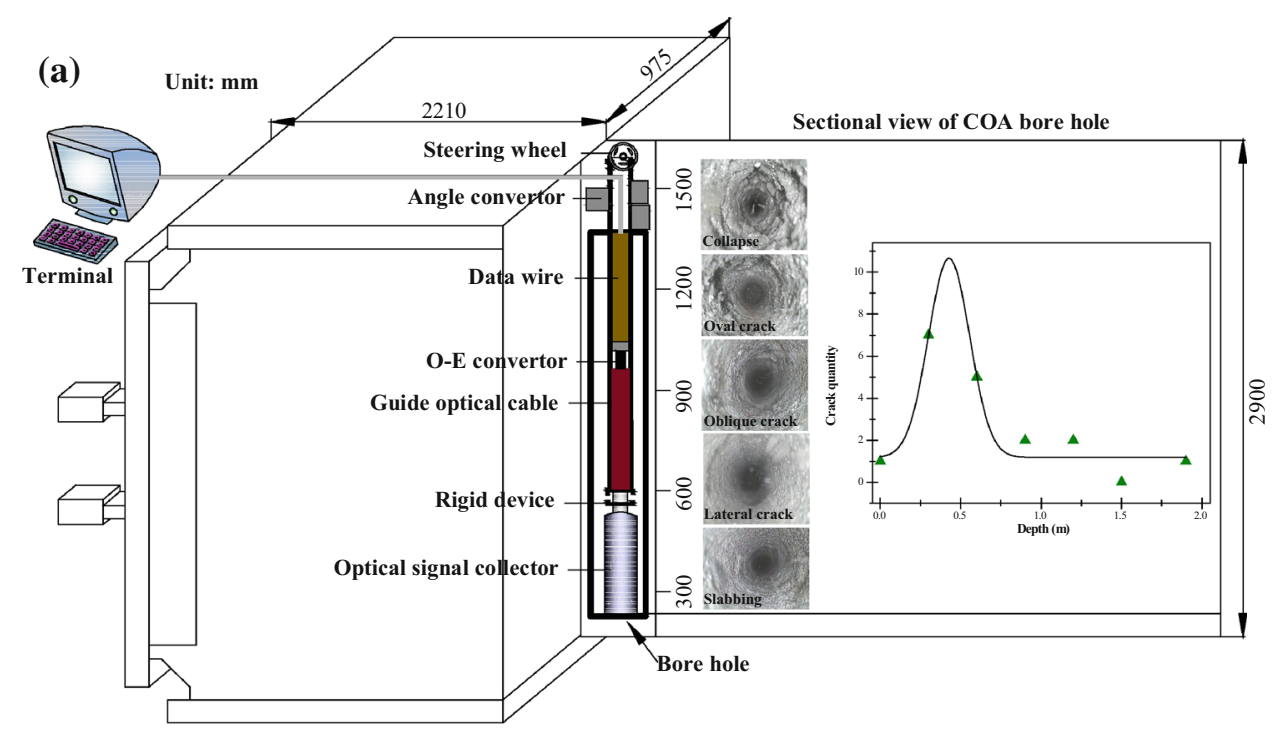

(b)

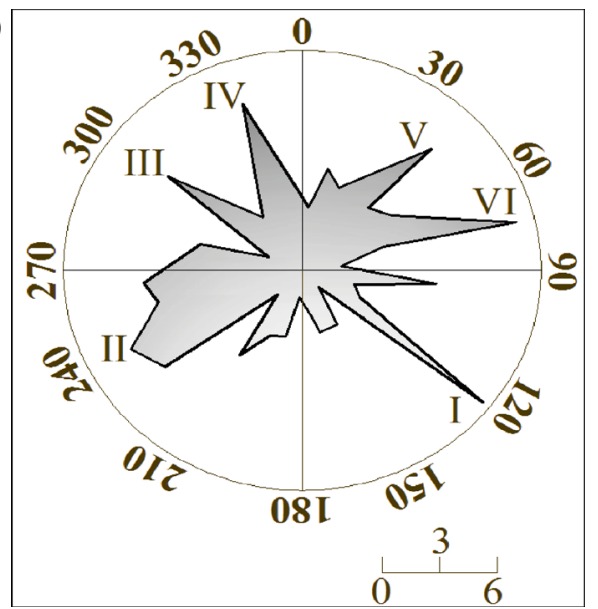

impact on the upper surrounding rock without large subsidence. Subsidence behavior of the points in row $b$ were consistent with those in row a. In the process of top coal caving, subsidence of the model fluctuated violently, and the maximum value was $0.20 \mathrm{~mm}$. Simultaneously, the crest value of subsidence in row c was $0.60 \mathrm{~mm}$. and the average value was $0.35 \mathrm{~mm}$. Subsidence of points in row d undulated sharply with the minimum values and maximum values being 0.22 and $0.58 \mathrm{~mm}$, respectively. Subsidence in row e and row $\mathrm{f}$ also fluctuated remarkably with the maximum value being 0.59 and $0.98 \mathrm{~mm}$, respectively.

According to these results, we conclude that subsidence of coal-rock masses had various characteristics in different stages of the model. During the coal caving, the subsidence values fluctuated more than in other stages. Also, quantity of caving coal affected the degree of asymmetric destabilization in the model, which means that we must control the stability of coal-rock masses by adjusting the quantity of caving coal.

\subsection{Observing Support Performance}

Researches on strata behavior in the extremely steep and thick coal seams indicate that parameter optimization would be needed for in-situ support (Lai et al. 2009a, b, 2014). According to various field loadings of surrounding rock, the support should be determined by comparing the theoretical analysis and numerical simulation results (Lai et al. 2009a, b). Yield loading of the in-situ supports has been set at $4500 \mathrm{kN}$ by simulation theories and setting loading must be $4200 \mathrm{kN}$. The simulated hydraulic support (Fig. 9a) has been installed in the working face with staticresistance strain equipment adopted for loading observation. The strain values fluctuated in the experiment and the coal caving process had a major impact on the support (Fig. 9b). A large-scale roof caving would increase the amount of shock to the support. Based on statistical results, the setting loading of the hydraulic support was between 4000 and $4200 \mathrm{kN}$, and also the phenomena that occurred 

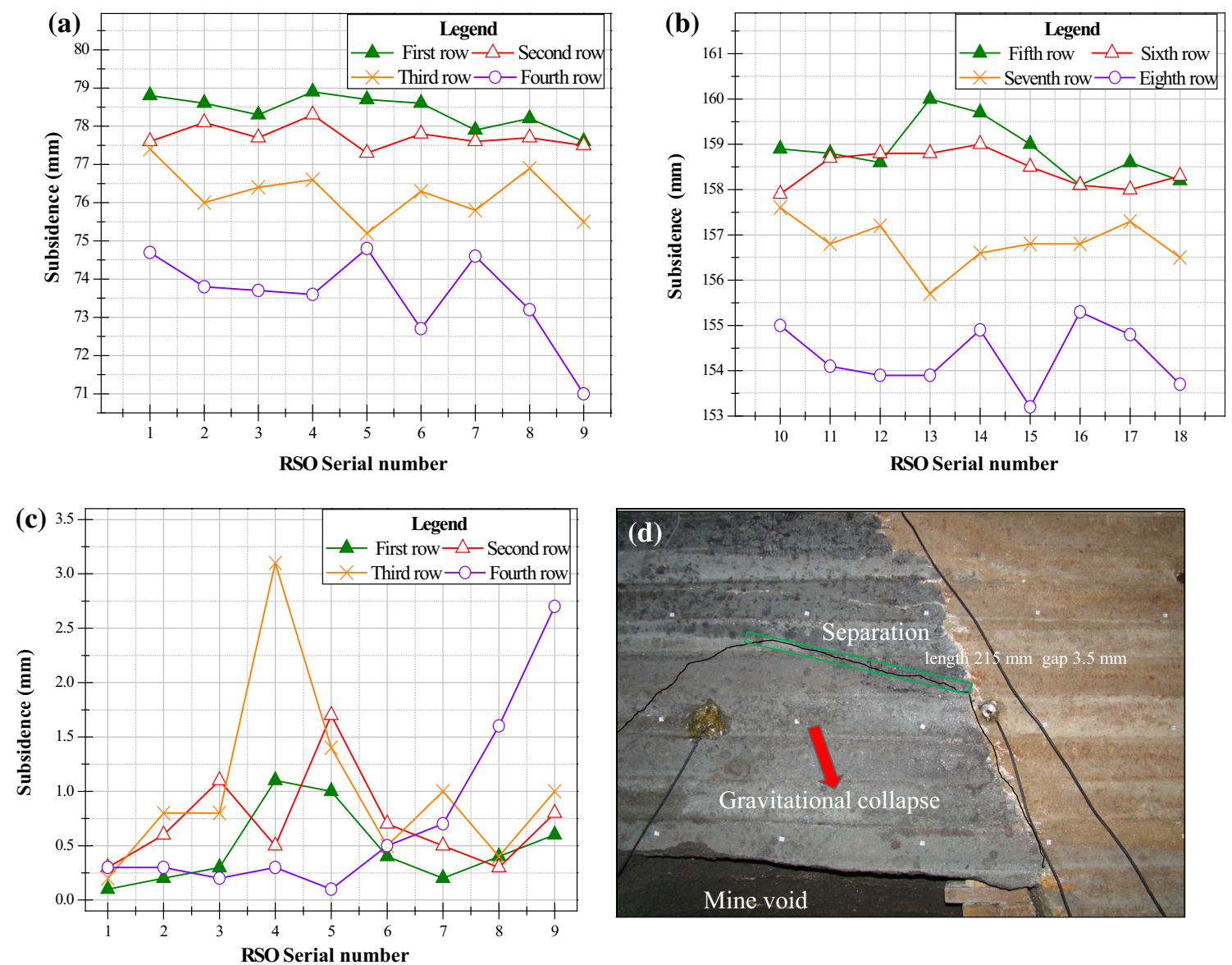

Fig. 7 Roof separation observation results for displacement of internal part of the model, a-c separately show roof separation characteristics. d Illustrates the actual separation emerged in the experiment

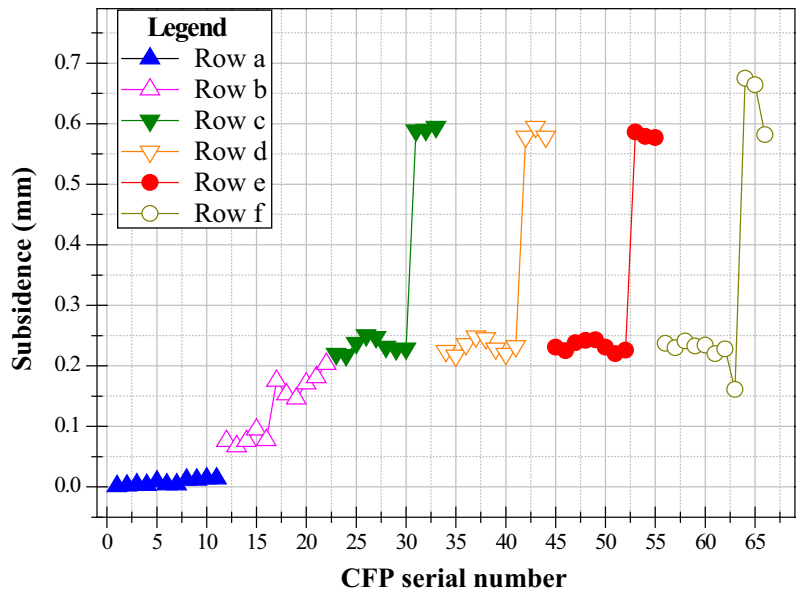

Fig. 8 Surface deformation monitoring by close-field photogrammetry under compressive loading

after first roof caving in the experiment were similar with the actual situation of roof failure. Particularly, the individual hydraulic support had such a low setting loading that they could not adequately maintain contact with the roof.
When the roof caved in a large-scale zone, the peak value of the support loading was up to $4200 \mathrm{kN}$; however, the simulated hydraulic support with $4200 \mathrm{kN}$ would ensure demand of pressure control.

\section{Discussion}

In the physical simulation experiment, asymmetric destabilization of surrounding rock around mine voids is an evolutionary process that is divided into three steps: initial failure step, separation fracture step, and three-hinge arch formation step. Figure 10 shows the asymmetric destabilization characteristics of coal-rock masses in different loading (initial failure step, separation fracture step, and three-hinge arch formation step) with the value of $M_{0}$ and $\Delta M_{0}$, respectively. All statistical data comply with the basic stress-strain relationship of the actual rock masses.

Also, we revealed the mechanisms of stress-strain-AE of surrounding rocks in the experiment. Figure 11 indicates the asymmetric destabilization characteristics under 

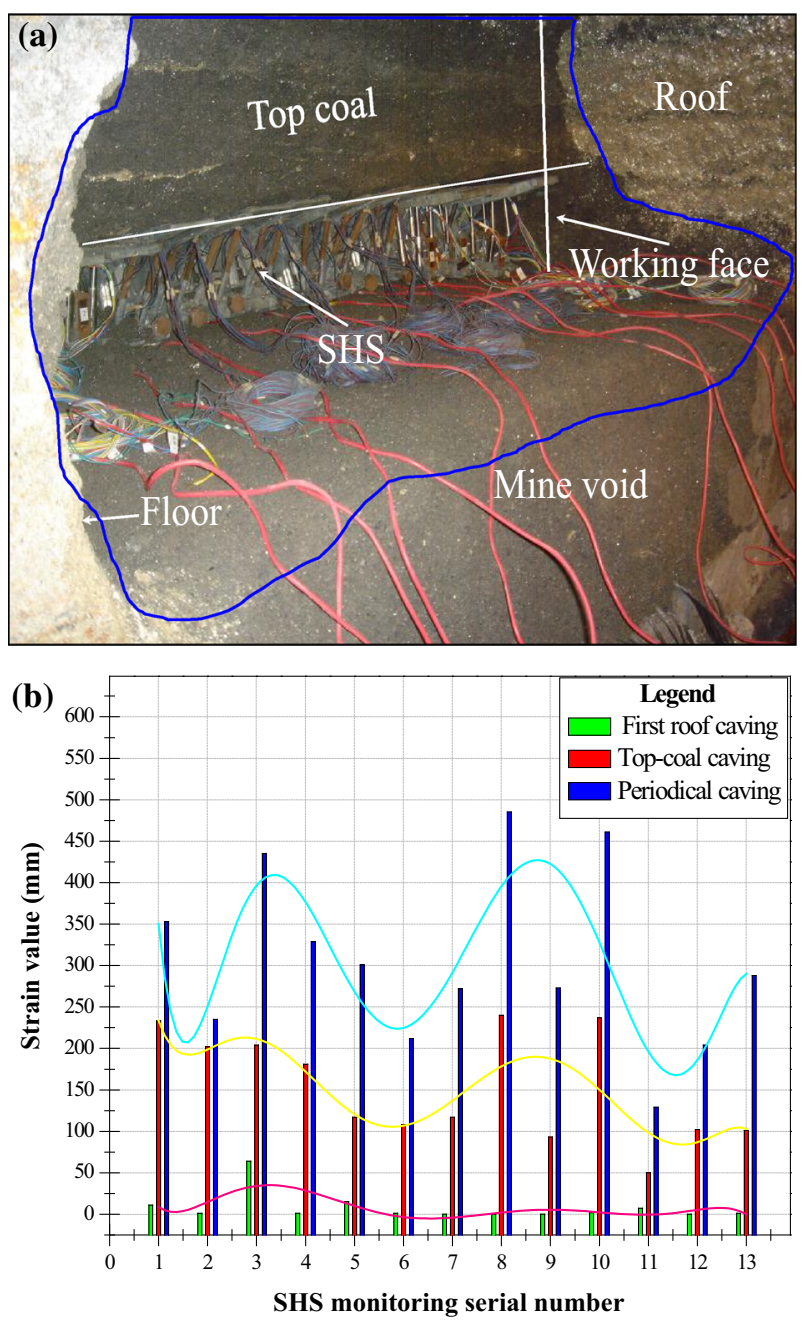

Fig. 9 Strain characteristics of the mechanized sub-horizontal section top coal caving working face by the simulated hydraulic support in first roof caving, top coal caving and periodic caving, a the real arrangement of the simulated hydraulic support; $\mathbf{b}$ the deformation value of the support

horizontal and vertical dynamic loading. The results show that the abnormal area of AE trait parameters are represented with micro-crack initiation, and yielding points in the stress curve were truly initial points of coal-rock mass failure, which accelerated the destabilization of the surrounding rock.

The acoustic source of AE under compressive loading is represented with two disparate types: (1) sources intensively distributed close to the host fracture plane of surrounding rock, and (2) sources sprinkled in the whole model with obvious variances in $\mathrm{AE}$ time sequences due to structural traits of the surrounding rock. In the same experimental setups and circumstance, different spatialtemporal distribution of $\mathrm{AE}$ may be induced by internal structure of coal-rock mass, densification of the coal-rock mass, and/or heterogeneity.
Asymmetric destabilization percentage of coal-rock masses $(A L D P)$ with consideration of variability of $\mathrm{AE}$ trait parameters and crack interaction observed in the experiment have been defined, which can visually respond to the asymmetric destabilization degree of the large-scale experimental model. The failure extent of the surrounding rock can be quantified by $A L D P$ using Eq. (11).

$A L D P=\frac{\sum\left(\text { Big } \_A E\right)}{\sum\left(\text { Total } \_A E\right)} \times 100 \%$
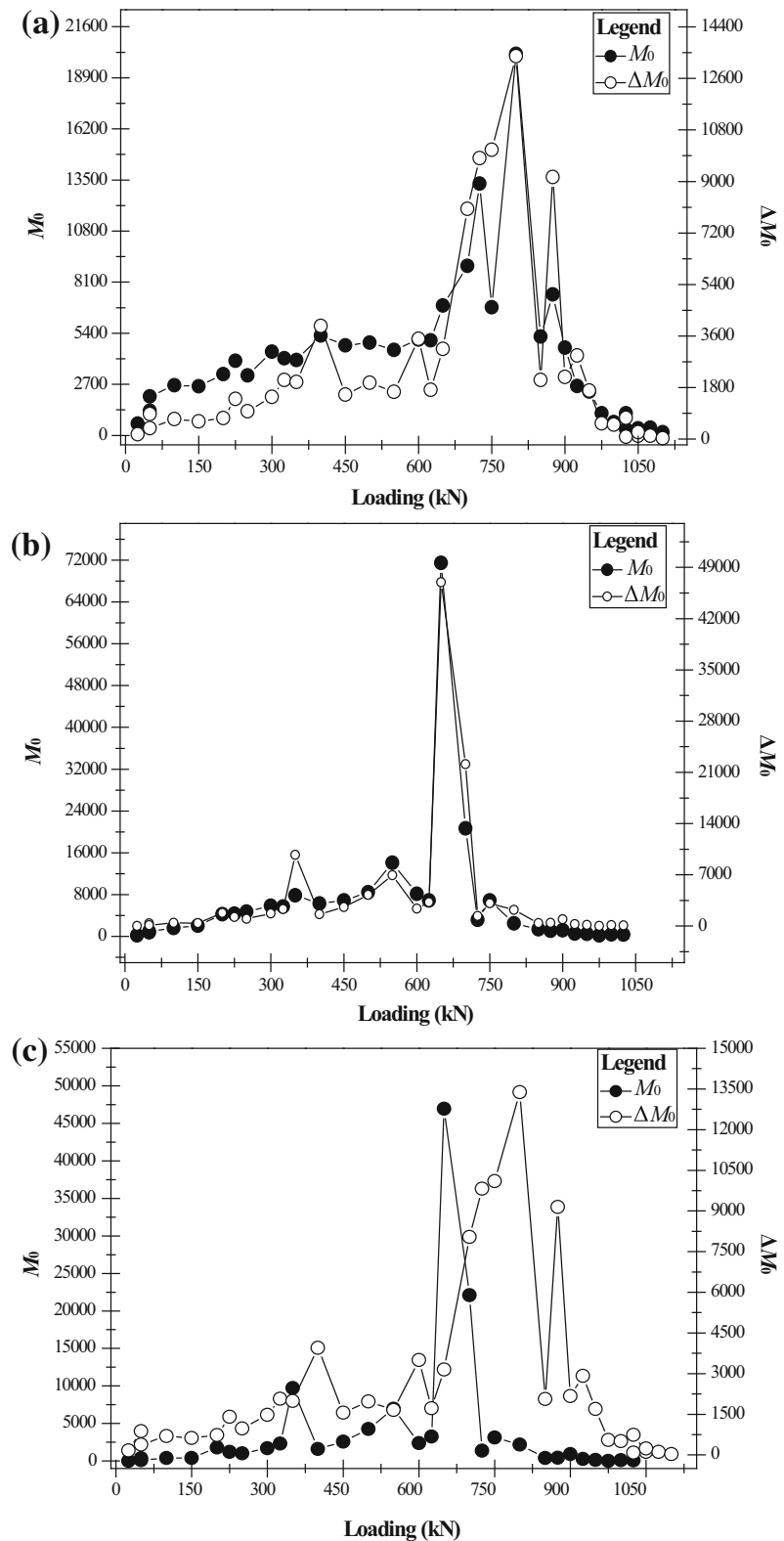

Fig. 10 Vector on damage-deformation-AE characteristics in different steps a initial failure step, $\mathbf{b}$ separation fracture step, and $\mathbf{c}$ threehinge arch formation step 
where, $\boldsymbol{\Sigma}$ (Big_AE) is accumulative amount of the AE big event, $\boldsymbol{\Sigma}$ (Total_AE) is accumulative amount of the AE total event. Also, Fig. 12 shows the ALDP degree under horizontal and vertical loading. Ultimately, $A L D P$ would be employed as an effective indicator for assessing asymmetric destabilization status of the surrounding rock, which will provide valid evidence for predicting and controlling dynamic hazards in ESTCS.

A four-channel AE digital signal processing instrument was used with in-situ monitoring, to obtain a new standard with the $A L D P$, whose result can apply for assessing the asymmetric destabilization in the Weihuliang coal mine. R15 with a $1220 \mathrm{~A}$ preamplifier as the transducer was used to detect the AE signals with a peak frequency response of $150 \mathrm{kHz}$. The preamplifiers had the ability to select the filter (high pass, low pass, or band pass), single ended or differential input, and gain. The gain in the actual operation was set at $40 \mathrm{~dB}$. Here, the mine-void surrounding rocks in $+574 \mathrm{~m}$ stope were loaded to failure with coal mining. We monitored AE signature at various stages including (I) excavation of working face, (II) first caving of top coal, (III) coal caving, and (IV) local roof caving for the asymmetric destabilization characteristics. The AE data (Table 5) indicates that all ALDP values in the in-situ monitoring were greater than $50 \%$. In the III stage, duration of the $\mathrm{AE}$ was longer than the duration in others. When the working face was extracted, the initial stress was disturbed by the excavation zone. However, the threshold of the asymmetric destabilization was from the final stage because of a larger energy rate and rise time of AE signals.

\section{Conclusions}

This study included a comprehensive site investigation of engineering, geological and geotechnical characterization of rock masses in the Weihuliang mine. The results of the

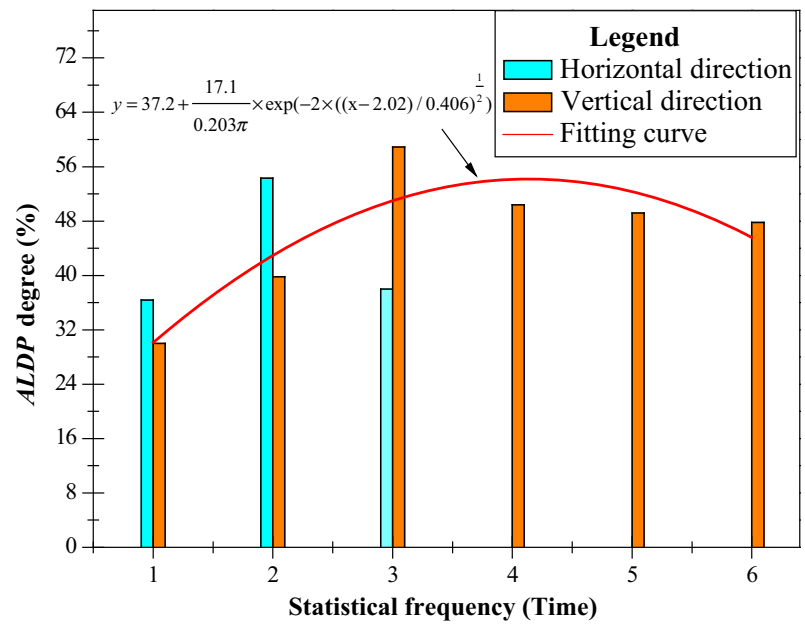

Fig. $12 A L D P$ degree under horizontal and vertical loading

investigation show that the fault-fold structure of northern Tianshan Mountain and the nappe structure of Bogda Mountain would increase tectonic stress to the mechanized sub-horizontal section top coal caving (SSTCC) face in extremely steep and thick coal seams (ESTCS), which was a crucial parameter in the simulation.

Based on field rock mass material characterization, physical-mechanical properties of rock masses, and relevant theory, we formed a new model material that could be used to accurately build a 3D geological model representative of the SSTCC. A non-systematic 3D physical modeling experiment was designed and implemented for simulating and characterizing asymmetric destabilization. The results of the 3D physical modeling experiment, combined with hybrid statistical methods show that asymmetric destabilization characteristics of coal-rock masses under different loading conditions would occur in three steps: initial failure step, separation fracture step, and
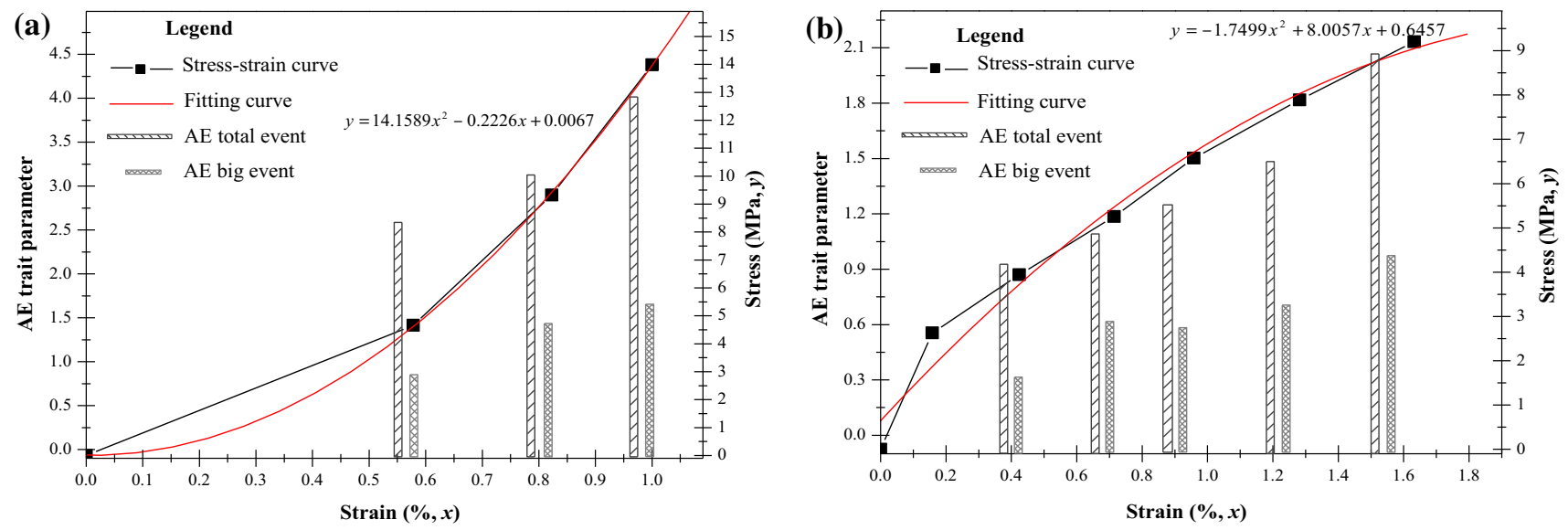

Fig. 11 Mechanism of stress-strain-AE of surrounding rock, a stress-strain-AE under horizontal dynamic loading; b stress-strain-AE under vertical dynamic loading 
Table 5 Specific matching ratios adopted for the model

\begin{tabular}{|c|c|c|c|c|c|c|c|}
\hline Serial number & $\Sigma($ Big_AE) & $\Sigma$ (Total_AE) & Duration $(\mu \mathrm{s})$ & Energy rate & Rise time $(\mu \mathrm{s})$ & $A L D P(\%)$ & Stage \\
\hline 1 & 54 & 99 & 2678.4 & 64 & 666 & 54.55 & Excavation of working face \\
\hline 2 & 17 & 31 & 2512.8 & 11 & 1402.2 & 54.84 & \\
\hline 3 & 10 & 17 & 4109.4 & 24 & 89.4 & 58.82 & \\
\hline 4 & 16 & 21 & 1227 & 5 & 26.4 & 76.19 & \\
\hline 5 & 145 & 178 & 2574.6 & 57 & 13.2 & 81.46 & \\
\hline 6 & 66 & 127 & 2116.2 & 39 & 634.8 & 51.97 & \\
\hline 7 & 20 & 38 & 1113.6 & 11 & 381.6 & 52.63 & First caving of top coal \\
\hline 10 & 158 & 190 & 3918 & 181 & 477 & 83.16 & \\
\hline 11 & 287 & 301 & 5802.6 & 414 & 993 & 95.35 & \\
\hline 12 & 87 & 129 & 2725.2 & 33 & 378 & 67.44 & Coal caving \\
\hline 13 & 29 & 47 & $11,581.2$ & 10 & 279.6 & 61.70 & \\
\hline 14 & 52 & 82 & 1914 & 30 & 1.8 & 63.41 & \\
\hline 15 & 45 & 49 & 5161.2 & 20 & 573 & 91.84 & \\
\hline 16 & 89 & 121 & 3117 & 59 & 1510.2 & 73.55 & \\
\hline 17 & 159 & 172 & 3769.2 & 229 & 460.8 & 92.44 & \\
\hline 18 & 234 & 245 & 5803.2 & 476 & 843.6 & 95.51 & \\
\hline 19 & 189 & 217 & 4052.4 & 184 & 748.2 & 87.10 & \\
\hline 20 & 154 & 177 & 3659.4 & 2090 & 2595.2 & 87.01 & Local roof caving \\
\hline 21 & 76 & 90 & 3034.8 & 7200 & 4436.2 & 84.44 & \\
\hline 22 & 128 & 178 & 3392.4 & 1570 & 3577.2 & 71.91 & \\
\hline 23 & 32 & 64 & 2973 & 3300 & 2361.2 & 50.00 & \\
\hline 24 & 102 & 169 & 6513 & 1200 & 4575.6 & 60.36 & \\
\hline
\end{tabular}

three-hinge arch formation step. The acoustic sources of AE under compressive loading were mainly distributed close to the primary fracture plane of the surrounding rock. Few sources were distributed throughout the entire model with variances in AE time sequence due to structural traits of the surrounding rock. We defined an indicator (ALDP) that could be used to predict and control dynamic hazards in ESTCS.

Acknowledgments Financial support for this work was provided by the 973 Key National Basic Research Program of China (No. 2014CB260404, No. 2015CB251600), the Key National Natural Science Foundation of China (No.U13612030), Shaanxi Innovation Team Program (No.2013KCT-16), and the High Technology Development Program of XinJiang Municipality (No. 201432102). Support from these agencies is gratefully acknowledged.

Open Access This article is distributed under the terms of the Creative Commons Attribution License which permits any use, distribution, and reproduction in any medium, provided the original author(s) and the source are credited.

\section{References}

Alehossein H, Poulsen BA (2010) Stress analysis of longwall top coal caving. Int J Rock Mech Min Sci 47(1):30-41

Cai MF, Ji HG, Wang JA (2005) Study of the time-space-strength relation for mining seismicity at Laohutai coal mine and its prediction. Int J Rock Mech Min Sci 42(1):145-151
Cao JT, Lai XP, Shan PF (2011) Hybrid analysis of dynamic destabilization to HSTCC workings in steep coal seams. In: The 2nd ISRM international young scholars' symposium on rock mechanics, 2011, pp 757-759

Castro R, Trueman R, Halim A (2007) A study of isolated draw zones in block caving mines by means of a large $3 \mathrm{D}$ physical model. Int J Rock Mech Min Sci 44:860-870

Dian C (1992) The state of the art and future of China thick seam mining technology. In: Singh TN, Dhar BB (eds) Proceedings of international symposium on thick seam mining. Central Mining Research Station, Dhanbad, pp 171-182

Diaz Aguado MB, Gonzalez C (2009) Influence of the stress state in a coal bump-prone deep coalbed: A case study. Int J Rock Mech Min Sci 46:333-345

Huang QX (2009) Simulation of clay aquifuge stability of water conservation mining in shallow-buried coal seam. Chin J Rock Mech Eng 28(5):988-992 (in Chinese)

Jha SN, Karmakar S (1992) Thick seam mining-some experience and exaltation. In: Singh TN, Dhar BB (eds) Proceedings of international symposium on thick seam mining. Central Mining Research Station, Dhanbad, pp 191-202

Kelly M, Balusu R, Hainsworth D (2001) Status of longwall research in CSIRO. In: Morgantown: Proceedings of 20th international conference on ground control in mining, 2001, pp 16-20

Kose H, Tatar C (1997) Underground mining methods. DEU, Izmir

Lai XP, Shan PF et al (2013) Large-three-dimensional physical simulation experiments on a high and steep slope stability of open-pit mines. In: 3rd ISRM symposium on Rock Mechanics, 2013, pp 425-430

Lai XP, Ren FH, Wu YP (2009a) Comprehensive assessment on dynamic roof instability under fractured rock mass conditions in 
the excavation disturbed zone. Int $\mathrm{J}$ Minerals Metall Materials 16(1):12-18

Lai XP, Wang NB, Xu HD et al (2009b) Safety top coal caving of heavy and steep coal seams under complex environment. J. Univ Sci Tech Beijing 31(3):277-280 (in Chinese)

Lai X, Shan P, Ren F et al (2012) Comparative Experiment on Strength of Multi-media Composite Simulate Materials in Mine's High and Steep Slope. J Xi'an Univ Sci Tech 32(2): $1-5$ (in Chinese)

Lai XP, Shan PF, Ren FH et al (2013) Application of model material PRCM in physical simulation experiment on slope's stability in mine's high and steep. Metal Mine 441(3):1-5 (in Chinese)

Lai XP, Shan PF, Cao JT et al (2014) Hybrid assessment of preblasting weakening to horizontal section top coal caving (HSTCC) in steep and thick seams. Int $\mathrm{J}$ Min Sci Tech 24(1):31-37

Lauriello PJ, Fritsch CA (1974) Design and economic constraints of thermal rock weakening techniques. Int J Rock Mech Min Sci Geo-Mech 11(1):31-44

Li TB, Wang XF, Meng LB (2011) Physical Simulation Study of Similar Materials for Rockburst. Chin J Rock Mech Eng 30(supp 1):2610-2616 (in Chinese)

Lin YM (1984) Lab of rock mechanics. Chinese Coal Industry Press, 58 (in Chinese)

Miao SJ, Lai XP, Cui F (2011) Top coal flows in an excavation disturbed zone of high section top coal caving of an extremely steep and thick seam. Min Sci Tech 21(01):99-107

Pan YS, Zhang MT, Wang LG et al (1997) Study on rockburst by equivalent material simulation tests. Chin J Geotech Eng 19(4):49-56 (in Chinese)

Simsir F, Ozfirat MK (2008a) Determination of the most effective longwall equipment combination in longwall top coal caving (LTCC) method by simulation modelling. Int J Rock Mech Eng 45(6):572-582

Simsir F, Ozfirat MK (2008b) Determination of the most effective longwall equipment combination in longwall top coal caving (LTCC) method by simulation modeling. Int J Rock Mech Min Sci 45(6):1015-1023
Singh R (1999) Mining methods to overcome geotechnical problems during underground working of thick coal seams-case studies. Trans Inst Min Metall Sec A Min Indus 108:121-131

Singh TN, Kushwaha A, Singh R, Singh R (1992) Strata behaviour during slicing of thick seam at East Katras Colliery. In: Singh TN, Dhar BB (eds) Proceedings of international symposium on thick seam mining. Central Mining Research Station, Dhanbad, pp 237-250

Trueman R, Castro R, Halim A (2008) Study of multiple draw-zone interaction in block caving mines by means of a large $3 \mathrm{D}$ physical model. Int J Rock Mech Min Sci 45(7):1044-1051

Tu SH, Yong Y, Zhen Y, Ma XT, Qi W (2009) Research situation and prospect of fully mechanized mining technology in thick coal seams in China. Proc Earth Plan Sci 1(1):35-40

Unver B, Yasitli NE (2006) Modeling of strata movement with a special reference to caving mechanism in thick seam coal mining. Int J Coal Geol 66(04):227

Vakili A, Hebblewhite BK (2010) A new cavability assessment criterion for Longwall Top Coal Caving. Int J Rock Mech Eng 47(8): 1317

Wu J (1992) The movement regularity of the roof coal around a longwall with caving and its coal recovery. In: Proceedings of international symposium on fully mechanized mining technology for high output and efficiency, 1992, pp 307-318

Xie YS, Zhao YS (2009) Numerical simulation of the top coal caving process using the discrete element method. Int J Rock Mech Min Sci 46(6):983-991

Yasitli NE, Unver B (2005) 3D numerical modeling of longwall mining with top coal caving. Int $J$ Rock Mech Min Sci 42:219-227

Zhang ZF, Lai XP (2008) Segment pre-blasting of sublevel caving of steep and thick coal seam under complex conditions. J Chin Coal Soc 33(8):845 (in Chinese)

Zhang JG, Zhao ZQ, Gao Y (2011) Research on top coal caving technique in steep and extra-thick coal seam. Proc Earth Plan Sci 2:145-151 